\title{
Defects in Rhizobial Cyclic Glucan and Lipopolysaccharide Synthesis Alter Legume Gene Expression During Nodule Development
}

\author{
Alejandra L. D'Antuono, ${ }^{1}$ Thomas Ott, ${ }^{2}$ Lene Krusell, ${ }^{2}$ Vera Voroshilova, ${ }^{2}$ Rodolfo A. Ugalde, ${ }^{1}$ \\ Michael Udvardi, ${ }^{2}$ Viviana C. Lepek ${ }^{1}$ \\ ${ }^{1}$ Instituto de Investigaciones Biotecnológicas, INTECH, Universidad Nacional de General San Martín, CONICET, \\ Buenos Aires, Argentina; ${ }^{2}$ Max-Planck-Institute of Molecular Plant Physiology, Golm, Germany
}

Submitted 15 June 2007. Accepted 4 October 2007.

\begin{abstract}
cDNA array technology was used to compare transcriptome profiles of Lotus japonicus roots inoculated with a Mesorhizobium loti wild-type and two mutant strains affected in cyclic $\beta(1-2)$ glucan synthesis (cgs) and in lipopolysaccharide synthesis (lps $\beta 2$ ). Expression of genes associated with the development of a fully functional nodule was significantly affected in plants inoculated with the $\operatorname{cgs}$ mutant. Array results also revealed that induction of marker genes for nodule development was delayed when plants were inoculated with the $\operatorname{lps} \beta 2$ mutant. Quantitative real-time reverse-transcriptase polymerase chain reaction was used to quantify gene expression of a subset of genes involved in plant defense response, redox metabolism, or genes that encode for nodulins. The majority of the genes analyzed in this study were more highly expressed in roots inoculated with the wild type compared with those inoculated with the $\operatorname{cgs}$ mutant strain. Some of the genes exhibited a transient increase in transcript levels during intermediate steps of normal nodule development while others displayed induced expression during the final steps of nodule development. Ineffective nodules induced by the glucan mutant showed higher expression of phenylalanine ammonia lyase than wild-type nodules. Differences in expression pattern of genes involved in early recognition and signaling were observed in plants inoculated with the $M$. loti mutant strain affected in the synthesis of cyclic glucan.
\end{abstract}

Additional keywords: competitiveness, infection threads, Lotus glaber, Nod factor perception, phenolic compounds

L. D'Antuono and T. Ott contributed equally to this work and are joint first authors.

Corresponding author: V. C. Lepek, Telephone: +1 54-11-4580-7255; Fax: +1 54-11-4752-9639, E-mail: vlepek@iib.unsam.edu.ar

Current address of T. Ott: Laboratoire Interactions Plantes Microorganismes (LIPM), INRA-CNRS Toulouse, Castanet Tolosan, France.

Current address of L. Krusell: Laboratory of Gene Expression, Department of Molecular and Structural Biology, University of Aarhus, DK-8000 Aarhus C, Denmark.

Current address of M. Udvardi: Plant Biology Division, The Samuel Roberts Noble Foundation, Ardmore, OK, U.S.A.

* The $\boldsymbol{e}$-Xtra logo stands for "electronic extra" and indicates that three additional tables are published online.
Development of symbiotic associations between rhizobia and legumes involve a complex molecular communication, which leads to transcriptional reprogramming of both partners (Barnett et al. 2004; Colebatch et al. 2002a and b, 2004; El Yahyaoui et al. 2004; Kouchi et al. 2004). Plant-derived flavonoids play important roles during initial steps of this interaction. They are secreted by plant roots into the rhizosphere and induce production of bacterial lipochito-oligosaccharide compounds called Nod factors (Zuanazzi et al. 1998). Nod factor perception by the plant triggers physiological and morphological changes, including root hair deformation and initiation of cortical cell divisions leading to nodule primordium formation (Gage 2004). Simultaneously, bacteria are entrapped in an infection pocket at the inner site of the curled root hair and enter the plant cell via infection threads (ITs) that arise as a tubular in-growth bounded by plant cell wall (Brewin 2004). Bacteria grow and divide inside ITs while these progress toward the root cortex. Finally, bacteria are released from ITs into plant cells in developing nodules by an endocytotic process where they differentiate into nitrogen-fixing bacteroids (Gage 2004; Udvardi and Day 1997).

Many plant genes involved in root nodule formation and nitrogen fixation were discovered during the past years. Plantsymbiotic mutants allowed the identification of several loci involved in different steps of the nodulation process (CaetanoAnolles and Gresshoff 1991; Endre et al. 2002; Limpens et al. 2003; Madsen et al. 2003; Radutoiu et al. 2003; Schauser et al. 1999; Stougaard 2000; Stracke et al. 2002; Szczyglowski et al. 1998). Among them were two LysM receptor-like kinase genes that were proposed to encode the putative Nod factor receptors in Lotus japonicus (NFRl and NFR5) (Madsen et al. 2003; Radutoiu et al. 2003) and in Medicago truncatula (LYK3 and LYK4) (Limpens et al. 2003). Another receptor-like kinase gene mediating both mycorrhizal and rhizobial signals further downstream of the signaling cascade was described in $L$. japonicus (SYMRK) (Stracke et al. 2002) and in M. truncatula (DMI2) (Endre et al. 2002). Schauser and associates (1999) demonstrated that the NIN gene, encoding a putative transcription factor, is indispensable for IT formation and initiation of nodule primordia. Calcium spiking, a physiological phenomenon observed upon Nod factor perception, currently is believed to be mediated by the putative Ca-channel regulators CASTOR/ POLLUX in L. japonicus and by DMII in M. truncatula (Imaizumi-Anraku et al. 2005, Peiter et al. 2007).

Different approaches, including differential or subtractive hybridization techniques, led to the identification of several other nodule-specific or nodule-enhanced genes, named nodu- 
lins (Cook et al. 1995; Dickstein et al. 1988; Gamas et al. 1996; Godiard et al. 2007; Jimenez-Zurdo et al. 2000; Szczyglowski et al. 1997).

More recently, large-scale expressed sequence tag (EST) and genome sequencing projects opened new perspectives for transcriptome research. Genes that are upregulated during symbiosis were predicted by in silico approaches (Fedorova et al. 2002; Journet et al. 2002; Lamblin et al. 2003; Tesfaye et al. 2006) or identified by using cDNA or oligonucleotide array technology (Barnett et al. 2004; Colebatch et al. 2002a and b, 2004; El Yahyaoui et al. 2004; Kouchi et al. 2004; Lohar et al. 2006; Mitra and Long 2004; Starker et al. 2006).

A series of bacterial mutants affected in polysaccharide synthesis were shown to be unable to infect plants successfully or to form functional bacteroids (Fraysse et al. 2003; Lepek and D'Antuono 2005; Spaink 2000). Recently, we described the isolation and characterization of $M$. loti cyclic $\beta(1-2)$ glucan synthesis $(c g s)$ and lipopolysaccharide synthesis (lps $\beta 2) \mathrm{mu}-$ tant strains (D'Antuono et al. 2005). The cgs mutant is unable to induce the formation of ITs. Although this strain was not affected in its capacity to trigger root hair curling and nodule formation, nodules that developed upon infection of L. glaber with this mutant were empty of bacteria (D'Antuono et al. 2005). The lps $\beta 2$ mutant synthesizes reduced amounts of $\mathrm{O}$ antigen-containing lipopolysaccharide (LPS) molecules compared with the wild-type strain. It induced formation of nodules that were indistinguishable from those formed by the wild-type strain; however, co-inoculation experiments revealed that it was out-competed by the wild-type strain. The fact that the $M$. loti lps $\beta 2$ mutant induces a higher number of ITs than the wild type led to the hypothesis that it might have a competitive disadvantage either in being released from the ITs to the nodule cells or in its multiplication inside the nodule cells (D'Antuono et al., 2005).

Extensive cDNA array analysis of $L$. japonicus roots inoculated with both mutant and wild-type strains was used to study how the nodulation process is regulated at the transcriptional level. The aim of this study was to correlate some morphological and physiological changes that occurred during the nodulation process with changes in the plant transcriptome. A focus was put on the analysis of plant defense genes because a question still remains regarding the extent to which such systems are differentially regulated during infection, nodule organogenesis, and symbiotic nitrogen fixation.

\section{RESULTS}

\section{Analysis of IT structures and bacterial release.}

The nodulation phenotype of $c g s$ and $\operatorname{lps} \beta 2$ mutants on $L$. glaber was characterized recently (D'Antuono et al. 2005). Because the cDNA arrays used in this study were based on ESTs derived from L. japonicus, the nodulation phenotype on this plant genotype was studied before carrying out the cDNA array experiments.

L. japonicus roots inoculated with the $\operatorname{cgs}$ mutant developed small white nodules, as was observed on L. glaber (D'Antuono et al. 2005). No ITs could be found when L. japonicus was inoculated with a $\operatorname{cgs}$ mutant strain that express constitutively the green fluorescence protein (GFP) (data not shown).

In agreement with our previous results with L. glaber, the lps $\beta 2$ mutant strain induced the formation of wild-type fixing nodules on L. japonicus. Moreover, microscopic analyses of roots inoculated with a 1:1 mixture of $d s R E D$-labeled $M$. loti wild-type and GFP-labeled M. loti lps $\beta 2$ strains revealed that both strains induced similar numbers of ITs (data not shown). After 20 days, plants developed normal and large fixing nodules; however, the recovery of the $\operatorname{lps} \beta 2$ mutant strain from the nodules was strongly reduced compared with the wild-type strain, with a competitiveness index of $10^{-4}$ (discussed below). These results support the previously formulated hypothesis that the affected step in lps $\beta 2$ mutant is the release or replication of the mutant inside nodule cells, and not IT formation (D'Antuono et al. 2005).

\section{Identification of differentially expressed genes using cDNA arrays.}

With the aim to understand how the nodulation process is regulated at a transcriptional level, transcriptome comparison between nodules and uninoculated Lotus roots was carried out previously (Colebatch et al. 2002a, 2004). This analysis also was made comparing inoculated roots at different postinoculation times with the uninoculated ones (Kouchi et al. 2004). Here, in order to correlate some morphological and physiological root changes with gene expression, we analyzed the transcriptome using bacterial mutants affected in some step of the nodulation for inoculation, and we related the results with gene expression differences observed between inoculated and uninoculated roots in a normal process.

To evaluate changes in gene expression during infection, RNA samples were obtained from roots inoculated with the wild-type or one of the two mutant strains at 7 and 28 days postinoculation (dpi) and from uninoculated and inoculated roots at $21 \mathrm{dpi}$. An enlarged version of the partially redundant cDNA array previously described (Colebatch et al. 2002a, 2004) was used. This array contained 9,600 EST clones derived from a mature and developing nodule EST library that were polymerase chain reaction (PCR) amplified and spotted onto nylon membranes (Ott et al. 2005). A significant differential expression value of twofold was used as a cut-off for further analysis. A complete list of genes can be found in Supplementary Table A. Examples of genes belonging to the different functional groups that were significantly induced in roots upon inoculation with the wild-type strain compared with the $\mathrm{cgs}$ mutant are shown in Table 1. Table 1 also shows the expression status in the comparison inoculated versus uninoculated roots at $21 \mathrm{dpi}$. The corresponding data were included in Supplementary Table B.

Most of the genes more highly expressed in plants inoculated with the wild type compared with the $c g s$ mutant strain at 28 dpi are genes induced in nodulated roots compared with noninoculated roots at $21 \mathrm{dpi}$ (Table 1). Furthermore, expression of these genes in roots inoculated with the wild-type strain is significantly higher at 28 than at 7 dpi (Table 1). Among these genes are several encoding transporters, transcription factors, and genes involved in nitrogen metabolism, signaling, and hormone metabolism. A majority of these genes was described earlier to be more highly expressed in nodules compared with uninoculated roots (Colebatch et al. 2004). In addition, several early and late nodulins were found to be more highly expressed in roots inoculated with the wild-type strain compared with those with the $c g s$ mutant strain.

Genes involved in redox metabolism also were found to be overexpressed $28 \mathrm{dpi}$ in roots inoculated with the wild-type compared with the cgs mutant. These data are in agreement with previous results describing the fact that functional nodules contain high antioxidative capacities (Matamoros et al 2003) due to the requirement to detoxify reactive oxygen species that mainly derive from leghemoglobin auto-oxidation (Günther et al. in press).

A group of genes is overexpressed at early stages of nodulation ( $7 \mathrm{dpi}$ ) in plants inoculated with the wild-type strain compared, with the cgs mutant, but not at $28 \mathrm{dpi}$. Some of these genes such as those encoding a calcium channel $\alpha-1-$ I subunit, an aquaporin protein PIP1-1, a pyruvate decarboxylase, an 
Table 1. Examples of differentially expressed Lotus japonicus genes, as determined by macroarray analysis, from a comparison between Mesorhizobium loti wild-type (wt) and cyclic $\beta(1-2)$ glucan synthesis (cgs) mutant inoculations ${ }^{\mathrm{a}}$

\begin{tabular}{|c|c|c|c|c|c|c|c|c|c|c|c|}
\hline \multirow[b]{3}{*}{ Clone ID } & \multirow[b]{3}{*}{ TC no. ${ }^{b}$} & \multirow[b]{3}{*}{ Best database match ${ }^{c}$} & \multicolumn{4}{|c|}{ Comparison wt and $\operatorname{cgs}$} & \multirow[b]{3}{*}{ Roots $^{d}$} & \multicolumn{4}{|c|}{ Comparison wt at } \\
\hline & & & \multicolumn{2}{|c|}{7 dpi } & \multicolumn{2}{|c|}{28 dpi } & & \multicolumn{2}{|c|}{28 and 7 dpi } & \multicolumn{2}{|c|}{7 and 28 dpi } \\
\hline & & & Ratio & $P$ value & Ratio & $P$ value & & Ratio & $P$ value & Ratio & $P$ value \\
\hline & & Nodulins & & & & & & & & & \\
\hline 29h12 & 14055 & Leghemoglobin (BI419226) & 5.546 & 0.0012 & 12.278 & 0.012 & Induced & 12.556 & 0.013 & $\ldots$ & $\ldots$ \\
\hline $90 \mathrm{~g} 2$ & 14782 & $\begin{array}{l}\text { Late nodulin Nlj16 [Lotus japonicus] } \\
\text { (CB828802) }\end{array}$ & 3.197 & 0.0025 & 15.749 & 0.041 & Induced & 12.366 & 0.043 & $\ldots$ & $\ldots$ \\
\hline $74 \mathrm{f} 12$ & 14488 & $\begin{array}{l}\text { EARLY NODULIN 36A } \\
\text { (CB827419) }\end{array}$ & 2.318 & 0.0006 & 7.531 & 0.012 & Induced & 6.698 & 0.012 & $\ldots$ & $\ldots$ \\
\hline $100 \mathrm{~b} 2$ & 8055 & $\begin{array}{l}\text { Early nodulin ENOD18 [Vicia faba] } \\
\text { (CB829623) }\end{array}$ & 3.325 & 0.008 & 13.642 & 0.005 & Induced & 11.761 & 0.005 & $\ldots$ & \\
\hline $69 \mathrm{f} 8$ & 8309 & $\begin{array}{l}\text { Nlj21 [Lotus japonicus] (CB827047) } \\
\text { Redox metabolism }\end{array}$ & - & - & 4.060 & 0.011 & Induced & 4.709 & 0.004 & $\cdots$ & $\ldots$ \\
\hline $54 a 7$ & 8588 & $\begin{array}{l}\text { Superoxide dismutase [Cicer } \\
\text { arietinum] (BI420186) }\end{array}$ & 9.022 & 0.002 & - & - & WC & - & $\ldots$ & - & $\cdots$ \\
\hline $27 \mathrm{~b} 7$ & 7989 & $\begin{array}{l}\text { Probable peroxidase (EC 1.11.1.7) } \\
\text { (clone PC42) (BI418380) }\end{array}$ & 4.019 & 0.006 & - & - & Induced & - & $\ldots$ & - & $\ldots$ \\
\hline $\begin{array}{l}2 \mathrm{~g} 6 \\
82 \mathrm{~b} 1\end{array}$ & $\begin{array}{l}16336 \\
7860\end{array}$ & $\begin{array}{l}\text { Oxidoreductase family [Arabidopsis } \\
\text { thaliana] (AW719328) } \\
\text { Proline oxidase precursor }\end{array}$ & - & - & 20.870 & 0.006 & Induced & 36.925 & 0.005 & $\ldots$ & $\ldots$ \\
\hline & & $\begin{array}{l}\text { [Arabidopsis thaliana] (CB828043) } \\
\text { Transport }\end{array}$ & - & - & 17.379 & $1.9010^{-6}$ & Induced & 18.828 & $1.954 \mathrm{E}-06$ & $\ldots$ & $\ldots$ \\
\hline $70 \mathrm{~d} 7$ & 8045 & $\begin{array}{l}\text { Sulfate transporter-related } \\
\text { [Arabidopsis thaliana] (CB827109) }\end{array}$ & - & - & 34.995 & 0.008 & Induced & 28.701 & 0.008 & $\cdots$ & $\ldots$ \\
\hline $\begin{array}{l}88 \mathrm{a} 3 \\
23 \mathrm{~h} 12\end{array}$ & $\begin{array}{l}\text { Singleton } \\
7806\end{array}$ & $\begin{array}{l}\text { Calcium channel } \alpha \text {-1-I subunit } \\
{[\text { Rattus norvegicus] }(\mathrm{CB} 828566)} \\
\text { Aquaporin protein PIP1;1 }\end{array}$ & 8.635 & 0.002 & - & - & WC & $\ldots$ & $\ldots$ & 4.417 & 0.033 \\
\hline & & [Medicago truncatula] (BI418198) & 5.220 & 1.841 & - & - & Repressed & $\ldots$ & $\ldots$ & 3.472 & $1.016 \mathrm{E}-05$ \\
\hline $56 \mathrm{~d} 8$ & 15862 & $\begin{array}{l}\text { Aquaporin-like transmembrane } \\
\text { channel protein (BI420390) }\end{array}$ & 3.760 & 0.0006 & - & - & Repressed & $\ldots$ & $\ldots$ & 3.833 & 0.006 \\
\hline $96 \mathrm{~d} 10$ & 16504 & $\begin{array}{l}\text { Sorbitol-like transporter [Glycine } \\
\text { max] (CB829289) }\end{array}$ & 3.202 & 0.011 & 11.745 & 0.009 & Induced & 9.094 & 0.009 & $\ldots$ & $\ldots$ \\
\hline $92 \mathrm{f} 5$ & Singleton & $\begin{array}{l}\text { Potassium transporter, putative } \\
\text { (KUP3/KT4/POT4) [Arabidopsis } \\
\text { thaliana] (CB828967.1) }\end{array}$ & 3.032 & 0.009 & - & - & Repressed & $\ldots$ & $\ldots$ & $\ldots$ & $\ldots$ \\
\hline $19 f 11$ & 16363 & $\begin{array}{l}\text { Sucrose transporter } 4 \text { protein } \\
\text { (AW720468) }\end{array}$ & 4.200 & 0.011 & - & - & Repressed & $\ldots$ & $\ldots$ & 2.298 & 0.027 \\
\hline $83 c 5$ & Singleton & $\begin{array}{l}\text { Mannitol transporter, putative } \\
\text { [Arabidopsis thaliana] (CB828147) }\end{array}$ & - & - & 4.369 & 0.012 & Induced & 4.642 & 0.010 & $\ldots$ & $\ldots$ \\
\hline $37 \mathrm{~g} 5$ & 7822 & $\begin{array}{l}\text { CF0 ATP synthase:SUBUNIT =9 } \\
\text { (BI417853) } \\
\text { Response to pathogens and other } \\
\text { external factors }\end{array}$ & 5.795 & 0.009 & - & - & WC & $\ldots$ & $\ldots$ & 3.084 & 0.035 \\
\hline $37 f 8$ & 9381 & PAL (BI417846) & 2.013 & 0.008 & - & - & WC & - & $\ldots$ & - & $\ldots$ \\
\hline $67 \mathrm{~h} 4$ & Singleton & PAL (CB826882) & - & - & 13.165 & 0.019 & Induced & 10.620 & 0.018 & $\ldots$ & $\ldots$ \\
\hline 41h1 & 13869 & $\begin{array}{l}\text { Avr9/Cf-9 rapidly elicited protein } 31 \\
\text { [Nicotiana tabacum] (BI419590) }\end{array}$ & 3.656 & 0.021 & - & - & WC & - & $\ldots$ & - & $\ldots$ \\
\hline $69 \mathrm{e} 5$ & 12768 & $\begin{array}{l}\text { Avr9/Cf-9 rapidly elicited protein } \\
264 \text { [Nicotiana tabacum] } \\
\text { (CB827033) }\end{array}$ & - & - & 6.908 & 0.023 & Induced & 7.333 & 0.023 & $\ldots$ & $\ldots$ \\
\hline $50 f 4$ & 14348 & $\begin{array}{l}\text { Snakin-1 [Solanum tuberosum] } \\
\text { (BI418686) }\end{array}$ & 3.080 & 0.038 & - & - & WC & - & $\ldots$ & - & $\ldots$ \\
\hline $84 \mathrm{f} 5$ & Singleton & $\begin{array}{l}\text { NLS-TIR-NBS disease resistance } \\
\text { Protein [Populus tremula] } \\
\text { (CB828263) }\end{array}$ & 2.415 & 0.020 & - & - & WC & - & $\ldots$ & - & $\ldots$ \\
\hline $37 \mathrm{~d} 2$ & 10233 & $\begin{array}{l}\text { NtPRp27-like protein [Solanum } \\
\text { tuberosum] (BI417829) }\end{array}$ & 5.081 & 0.003 & - & - & Repressed & - & $\ldots$ & - & $\ldots$ \\
\hline $31 \mathrm{a} 6$ & 8688 & $\begin{array}{l}\text { Endo-1,4- } \beta \text {-D-glucanase }[\text { Pyrus } \\
\text { communis }] \text { (BI417870) }\end{array}$ & 2.341 & 0.011 & - & - & Induced & - & $\ldots$ & - & $\ldots$ \\
\hline $32 \mathrm{c} 9$ & 15071 & $\begin{array}{l}\text { Disease resistance response protein- } \\
\text { related/dirigent protein-related } \\
\text { (DRRP) (BI417979) } \\
\text { Cytochrome P450 71D11 }\end{array}$ & 2.563 & 0.019 & - & - & Repressed & - & $\ldots$ & - & $\ldots$ \\
\hline & & (CB828362) & - & - & 2.907 & 0.016 & Induced & - & $\begin{array}{c}\ldots \\
\text { (continue }\end{array}$ & $\overline{-}$ & ing page) \\
\hline
\end{tabular}

\footnotetext{
${ }^{a}$ Expression ratios are given for comparisons of different strain inoculations and different timepoints. A selection of ratios higher than twofold with $P$ value, obtained from Student $t$ test, $\leq 0.05$ is shown; dpi $=$ days postinoculation.

b $\mathrm{TC}=$ tentative consensus sequence.

${ }^{c}$ GenBank accession numbers are given in parenthesis. Phenylalanine ammonia-lyase $=$ PAL.

${ }^{\mathrm{d}}$ Comparison of inoculated and uninoculated roots at $21 \mathrm{dpi}$. WC $=$ without change.
} 
Table 1. (continued from preceding page)

\begin{tabular}{|c|c|c|c|c|c|c|c|c|c|c|c|}
\hline \multirow[b]{3}{*}{ Clone ID } & \multirow[b]{3}{*}{ TC no. ${ }^{b}$} & \multirow[b]{3}{*}{ Best database match ${ }^{c}$} & \multicolumn{4}{|c|}{ Comparison wt and $\operatorname{cgs}$} & \multirow[b]{3}{*}{ Roots $^{d}$} & \multicolumn{4}{|c|}{ Comparison wt at } \\
\hline & & & \multicolumn{2}{|c|}{7 dpi } & \multicolumn{2}{|c|}{$28 \mathrm{dpi}$} & & \multicolumn{2}{|c|}{28 and $7 \mathrm{dpi}$} & \multicolumn{2}{|c|}{7 and 28 dpi } \\
\hline & & & Ratio & $P$ value & Ratio & $P$ value & & Ratio & $P$ value & Ratio & $P$ value \\
\hline $88 \mathrm{~g} 6$ & 19604 & $\begin{array}{l}\text { Wound-induced protein-tomato } \\
\text { (fragment) (CB828625) }\end{array}$ & 4.000 & 0.006 & - & - & WC & - & $\ldots$ & - & $\ldots$ \\
\hline $67 \mathrm{c} 2$ & 14525 & $\begin{array}{l}\text { Isoliquiritigenin } 2^{\prime}-O- \\
\text { methyltransferase-alfalfa } \\
\text { >gi|13399462| (CB826820.1) }\end{array}$ & 2.894 & 0.049 & 6.216 & 0.001 & Induced & - & $\cdots$ & - & $\cdots$ \\
\hline $77 \mathrm{~b} 3$ & 14197 & $\begin{array}{l}\text { Hormone related } \\
\text { Auxin-repressed protein [Robinia } \\
\text { pseudoacacia] (CB827639) }\end{array}$ & - & - & 7.301 & 0.002 & Induced & 8.852 & 0.002 & $\ldots$ & $\ldots$ \\
\hline $92 \mathrm{~b} 9$ & 14714 & $\begin{array}{l}\text { INDOLE-3-ACETIC ACID } \\
\text { INDUCED PROTEIN ARG2 } \\
\text { (CB828926) }\end{array}$ & - & - & 6.135 & 0.001 & Induced & 3.719 & 0.001 & $\ldots$ & $\ldots$ \\
\hline $92 \mathrm{~d} 4$ & 14222 & $\begin{array}{l}\text { 1-Aminocyclopropane-1-carboxylate } \\
\text { oxidase (ACC oxidase) (ethylene- } \\
\text { forming enzyme) (CB828944) }\end{array}$ & - & - & 15.410 & 0.015 & Induced & 11.707 & 0.015 & $\cdots$ & $\cdots$ \\
\hline $74 \mathrm{e} 11$ & 8520 & $\begin{array}{l}\text { Transcription } \\
\text { Tuber-specific and sucrose- } \\
\text { responsive element binding factor } \\
\text { (CB827409) }\end{array}$ & 5.462 & 0.013 & 7.219 & 0.012 & Induced & 8.752 & 0.011 & $\ldots$ & $\ldots$ \\
\hline $97 \mathrm{~g} 10$ & 14538 & $\begin{array}{l}\text { CCCH-type zinc finger protein- } \\
\text { related [Arabidopsis thaliana] } \\
\text { (CB829404) }\end{array}$ & 3.867 & 0.012 & 14.153 & 0.032 & Induced & - & $\ldots$ & - & $\ldots$ \\
\hline $76 \mathrm{~g} 8$ & Singleton & $\begin{array}{l}\text { DHHC-type zinc finger domain- } \\
\text { containing protein [Arabidopsis } \\
\text { thaliana] (CB827611) }\end{array}$ & 2.132 & 0.0004 & 5.902 & 0.008 & Induced & - & $\ldots$ & - & $\ldots$ \\
\hline $40 f 11$ & 18247 & $\begin{array}{l}\text { KH domain protein [Arabidopsis } \\
\text { thaliana] (BI419487) } \\
\text { Other metabolisms }\end{array}$ & 3.895 & 0.001 & - & - & WC & - & $\cdots$ & - & $\cdots$ \\
\hline $85 \mathrm{~d} 2$ & 14104 & $\begin{array}{l}\text { Asparagine synthetase } \\
\text { [glutaminehydrolyzing] } 2 \\
\text { CB828330) }\end{array}$ & - & - & 12.492 & 0.004 & Induced & 10.013 & 0.004 & $\ldots$ & $\ldots$ \\
\hline $90 \mathrm{c} 4$ & 8402 & $\begin{array}{l}\text { Glyceraldehyde 3-phosphate } \\
\text { dehydrogenase, cytosolic } \\
\text { (CB828758) }\end{array}$ & 5.844 & 0.010 & 10.806 & 0.003 & Induced & 10.015 & . & - & $\ldots$ \\
\hline $93 \mathrm{~g} 5$ & 14491 & $\begin{array}{l}\text { Aspartate aminotransferase [Lotus } \\
\text { corniculatus var. japonicus] } \\
\text { (CB829072) }\end{array}$ & - & - & 9.575 & 0.002 & Induced & - & $\ldots$ & - & $\ldots$ \\
\hline $12 \mathrm{e} 4$ & 7962 & $\begin{array}{l}\text { Alcohol dehydrogenase } 1 ; \text { ADH1 } \\
\text { [Lotus corniculatus] (AW719956) }\end{array}$ & 8.017 & 0.002 & - & - & Repressed & - & $\ldots$ & - & $\ldots$ \\
\hline $76 f 3$ & 14068 & $\begin{array}{l}\text { Thiamin biosynthetic enzyme } \\
\text { [Glycine max] (CB827595) }\end{array}$ & 7.611 & 0.005 & - & - & WC & - & $\ldots$ & - & $\ldots$ \\
\hline $64 b 1$ & 7922 & $\begin{array}{l}\text { Pyruvate decarboxylase } 1 \text { [Lotus } \\
\text { corniculatus] (BI421001) }\end{array}$ & 3.991 & 0.036 & - & - & Repressed & $\ldots$ & $\ldots$ & 3.293 & 0.047 \\
\hline $41 \mathrm{~b} 12$ & 9707 & $\begin{array}{l}\text { Sterol delta-7 reductase } \\
\left(\mathrm{BI} 4^{\circ} 9531.1\right)\end{array}$ & 4.063 & 0.009 & - & - & Repressed & $\ldots$ & $\ldots$ & $\ldots$ & $\ldots$ \\
\hline $88 \mathrm{~g} 9$ & 14425 & $\begin{array}{l}\text { Putative chorismate mutase } \\
\text { precursor [Oryza sativa (japonica } \\
\text { cultivar-group)] (BI419531) }\end{array}$ & - & - & 13.072 & 0.007 & Induced & 12.195 & 0.007 & $\cdots$ & $\cdots$ \\
\hline $15 \mathrm{~h} 7$ & 8009 & $\begin{array}{l}\text { Cytosolic phosphoglycerate kinase } \\
{[\text { Pisum sativum }] \text { (AW720663) }}\end{array}$ & 3.424 & 0.016 & 8.956 & 0.009 & Induced & - & $\ldots$ & - & $\ldots$ \\
\hline $18 \mathrm{~b} 1$ & 10832 & $\begin{array}{l}\text { Arginine/serine-rich protein, } \\
\text { putative (AW720583) } \\
\text { Cell growth and wall synthesis }\end{array}$ & 3.799 & 0.0004 & 0.674 & 0.043 & Repressed & $\ldots$ & $\ldots$ & 3.621 & 0.0004 \\
\hline $60 \mathrm{e} 1$ & 14075 & $\begin{array}{l}\text { Hydroxyproline-rich protein-- } \\
\text { soybean (BI420695) }\end{array}$ & 3.506 & 0.015 & - & - & Repressed & - & $\cdots$ & - & $\cdots$ \\
\hline $32 \mathrm{e} 11$ & 8787 & $\begin{array}{l}\text { Putative extensin [Oryza sativa] } \\
\text { (BI417994) }\end{array}$ & 6.245 & 0.006 & - & - & WC & - & $\ldots$ & - & $\ldots$ \\
\hline $22 \mathrm{~g} 8$ & 14476 & $\begin{array}{l}\text { TUBULIN } \beta-1 \text { CHAIN } \\
\text { (AW720428) } \\
\text { Signaling }\end{array}$ & 3.049 & 0.001 & - & - & Repressed & $\ldots$ & $\ldots$ & 2.059 & 0.004 \\
\hline $23 \mathrm{~h} 2$ & 15125 & $\begin{array}{l}\text { EST AU070346(S12172) } \\
\text { corresponds to a region of the } \\
\text { predicted gene. Approximately } \\
\text { similar to AMP-binding protein } \\
\text { (BI418199) }\end{array}$ & 5.722 & 0.016 & - & _- & Repressed & & $\ldots$ & 4.902 & 0.018 \\
\hline $87 \mathrm{~d} 3$ & 16248 & $\begin{array}{l}\text { Receptor protein kinase-like protein } \\
\text { [imported]-[Arabidopsis thaliana] }\end{array}$ & & & & & & & & & \\
\hline $12 \mathrm{~h} 3$ & 8589 & $\begin{array}{l}\text { (CB828513) } \\
\text { RAB5B [Lotus corniculatus var. }\end{array}$ & 3.199 & 0.007 & 8.815 & 0.002 & Induced & - & $\ldots$ & - & $\ldots$ \\
\hline & & japonicus] (AW719977) & 6.539 & 0.009 & - & - & WC & - & $\ldots$ & - & $\ldots$ \\
\hline
\end{tabular}


arginine/serine-rich protein, a sterol $\delta$-7 reductase, a superoxide dismutase, a probable peroxidase, a tubulin $\beta-1$ chain, and a RAB5B, are repressed or not significantly altered when comparing wild-type inoculated with noninoculated control plants at $21 \mathrm{dpi}$ (Table 1). Expression of some of these genes also was detected as being significantly higher at 7 than at $28 \mathrm{dpi}$ in the wild-type inoculation. These results suggest that those genes display a transient induction during nodulation, a process not occurring in plants inoculated with the cgs mutant.

Global comparison of root gene expression profiles $7 \mathrm{dpi}$ with both mutants revealed similar significant underexpression of genes involved in sugar and protein metabolism, transcription, redox metabolism, response to pathogens, hormonal response, and transport, as well as some encoding for nodulins compared with roots inoculated with the wild-type strain. At $28 \mathrm{dpi}$, the differences were much less pronounced in lps $\beta 2$ mutant- than in cgs mutant-inoculated plants.

\section{Kinetic analysis of nodulin, defense-, and} redox-related genes during nodulation.

Array analysis at 7 and 28 dpi revealed that expression of a number of genes depends on the bacterial genotype and on the time after inoculation. Among them were genes putatively involved in redox metabolism and plant defense response. It remains to be elucidated to what extent plant defense responses are triggered during nodulation; therefore, several genes were studied in more detail using quantitative reverse-transcriptase (qRT)-PCR. Genes involved in these processes were chosen based on their differential expression observed in transcriptome analysis (Table 2). To get a more complete view, other genes described in independent studies to be involved in defense responses were included in this analysis. Among them were genes encoding a resistant-specific protein-3 (RES3) (TC 8082), a pathogenesis-related protein PR10-1 (PR10-1) (TC 15006), a putative flavanone 3-hydroxylase $(F 3 H)$ (TC 7931), a peroxidase $(P X)$ (TC 14066), a giberellin-2 oxidase $(G A-2$ OXIDASE) (TC 8129), and a putative WRKY transcription factor NtSub-D48 (NTSUB-D48) (TC 9957) (Table 2). Expression levels were studied at 7, 14, and 21 dpi in roots of plants inoculated with the wild-type or the mutant strains.

$N L J 21$ was significantly induced in roots of plants inoculated with the wild-type or the $\operatorname{lps} \beta 2$ strain, with the highest expression detected 21 dpi. Such induction was not found in roots inoculated with the cgs mutant (Table 2). Additionally, significantly increased transcript levels of gene encoding superoxide dismutase $(S O D)$ were observed in plants inoculated with the wild-type strain during intermediate time of nodulation, whereas no induction was detected in plants inoculated with the $\operatorname{cgs}$ mutant (Table 2). On the other hand, expression levels of the genes encoding phenylalanine ammonia lyase $(P A L)$ and NtSub-D48 were more highly expressed in roots inoculated with the $c g s$ mutant than with the wild-type or lps $\beta 2$ mutant. These results reveal some of the molecular differences comparing nodule development between the wild-type and the cgs mutant.

Based on the results presented in Table 2, genes were divided into two major groups according to their temporal expression pattern throughout the symbiotic process. The first group comprised genes that are induced in mature nodules (21 dpi) hosting wild-type bacteria. This pattern was found for genes encoding Nlj21, ENOD40, GA-2 oxidase, snakin1, PAL, and F3H. These genes, except PAL, were not expressed in nodule-like structures induced by the cgs mutant. A second group comprised genes that displayed maximum expression in immature, developing nodules. These included those encoding SOD, RES 3, endo-1,4- $\beta$-D-glucanase, peroxidase, NLS Toll-interleukin receptor nucleotide binding site (TIR-NBS) disease resistance protein, NtPRp27-like protein, and PR10-1. None of these genes was found to be induced in plants inoculated with the $\operatorname{cgs}$ mutant. Expression patterns of $S O D, N L S-T I R-N B S$, and a gene encoding endo$1,4-\beta$-D-glucanase were similar in plants inoculated with the lps $\beta 2$ mutant compared with the wild-type strain, although at lower levels. On the other hand, expression levels of $P X$,

Table 2. Expression levels were determined by quantitative reverse-transcriptase polymerase chain reaction and calculated as ratios compared with uninoculated control roots

\begin{tabular}{|c|c|c|c|c|c|c|c|c|c|}
\hline \multirow[b]{3}{*}{ Gene } & \multicolumn{9}{|c|}{ Relative transcript level } \\
\hline & \multicolumn{3}{|c|}{7 dpi } & \multicolumn{3}{|c|}{14 dpi } & \multicolumn{3}{|c|}{21 dpi } \\
\hline & $\operatorname{cgs}$ & lps & wt & $\operatorname{cgs}$ & lps & wt & $\operatorname{cgs}$ & lps & wt \\
\hline $\begin{array}{l}\text { NLJ21 (CB827047) } \\
\text { ENOD40 }\end{array}$ & $1.16 \pm 0.11$ & $0.34 \pm 0.07$ & $0.52 \pm 1 \mathrm{E}^{04}$ & $1.15 \pm 0.14$ & $0.88 \pm 0.40$ & $2.00 \pm 0.98$ & $1.41 \pm 0.46$ & $2.94 \pm 0.29$ & $4.09 \pm 0.75$ \\
\hline \multirow{2}{*}{\multicolumn{10}{|c|}{$\begin{array}{l}\text { (CB827419) } \\
\text { Endoglucanase- } \\
\text { encoding gene }\end{array}$}} \\
\hline & & & & & & & & & \\
\hline RES3 (CB827541) & $0.41 \pm 0.01$ & $0.49 \pm 0.01$ & $0.64 \pm 0.01$ & $0.85 \pm 0.05$ & $0.98 \pm 0.07$ & $2.31 \pm 0.34$ & $1.14 \pm 0.01$ & $1.36 \pm 0.01$ & $1.13 \pm 0.22$ \\
\hline$N L S$ (CB828263) & $0.57 \pm 0.02$ & $1.11 \pm 0.14$ & $0.92 \pm 0.06$ & $1.32 \pm 0.20$ & $2.11 \pm 0.11$ & $2.45 \pm 0.57$ & $1.49 \pm 0.26$ & $1.52 \pm 0.03$ & $1.21 \pm 0.28$ \\
\hline DRRP (BI417979) & $1.44 \pm 0.03$ & $1.72 \pm 0.01$ & $1.62 \pm 0.03$ & $0.71 \pm 0.12$ & $0.87 \pm 0.12$ & $0.73 \pm 0.11$ & $0.72 \pm 0.01$ & $0.78 \pm 0.05$ & $0.48 \pm 0.05$ \\
\hline $\begin{array}{l}\text { SNAKIN-I } \\
\text { (BI418686) }\end{array}$ & $0.50 \pm 0.05$ & $1.03 \pm 0.02$ & $0.98 \pm 0.02$ & $0.57 \pm 0.07$ & $1.19 \pm 0.06$ & $1.50 \pm 0.42$ & $1.02 \pm 0.07$ & $1.91 \pm 0.07$ & $2.11 \pm 0.98$ \\
\hline PR10-(BI417503.1) & $0.36 \pm 0.01$ & $0.71 \pm 0.03$ & $0.82 \pm 0.04$ & $0.94 \pm 0.32$ & $1.18 \pm 0.15$ & $2.14 \pm 0.50$ & $1.63 \pm 0.03$ & $1.59 \pm 0.04$ & $0.97 \pm 0.06$ \\
\hline \multicolumn{10}{|l|}{ NTPRP27 } \\
\hline (BI417829) & 0.06 & $0.83 \pm 0.05$ & $1.26 \pm 0.08$ & $1.40 \pm 0.56$ & $1.41 \pm 0.61$ & $5.84 \pm 2.02$ & $1.88 \pm 0.46$ & $2.28 \pm 0.14$ & $1.15 \pm 0.36$ \\
\hline F3H (BI419517) & $0.58 \pm 0.04$ & $2.20 \pm 0.10$ & $2.21 \pm 0.51$ & $2.00 \pm 0.56$ & $2.62 \pm 0.62$ & $4.34 \pm 1.44$ & $3.76 \pm 0.71$ & $13.72 \pm 4.06$ & $12.03 \pm 4.96$ \\
\hline SOD (BI420186) & $0.34 \pm 0.00$ & $0.63 \pm 0.01$ & $0.79 \pm 0.03$ & $1.23 \pm 0.39$ & $1.92 \pm 0.37$ & $3.80 \pm 0.29$ & $0.90 \pm 0.03$ & $1.12 \pm 0.04$ & $0.65 \pm 0.07$ \\
\hline$P X(\mathrm{BI} 418564.1)$ & $0.39 \pm 0.02$ & $0.56 \pm 0.00$ & $0.77 \pm 0.08$ & $1.25 \pm 0.40$ & $1.09 \pm 0.16$ & $2.19 \pm 0.22$ & $1.18 \pm 0.01$ & $1.61 \pm 0.02$ & $1.15 \pm 0.09$ \\
\hline \multicolumn{10}{|l|}{ GA 2-OXIDASE } \\
\hline PAL (BI417846) & $0.88 \pm 0.04$ & $0.66 \pm 0.09$ & $0.39 \pm 0.25$ & $1.40 \pm 0.54$ & $1.60 \pm 0.68$ & $2.87 \pm 0.56$ & $11.31 \pm 3.31$ & $1.85 \pm 0.51$ & $3.01 \pm 1.17$ \\
\hline \multicolumn{10}{|l|}{ NTSUB-D48 } \\
\hline (BI417354.1) & $0.35 \pm 0.05$ & $0.63 \pm 0.10$ & $0.81 \pm 0.15$ & $1.39 \pm 0.21$ & $1.88 \pm 0.16$ & $1.47 \pm 0.07$ & $3.24 \pm 0.25$ & $1.57 \pm 0.09$ & $1.11 \pm 0.65$ \\
\hline
\end{tabular}

${ }^{a}$ Data were normalized to ubiquitin. Abbreviations: dpi = days postinoculation, $\operatorname{cgs}=$ cyclic $\beta(1-2)$ glucan synthesis mutant, lps $=$ lipopolysaccharide synthesis mutant, and $\mathrm{wt}=$ wild-type strain. Maximal expression levels for each strain are in bold.

${ }^{\mathrm{b}}$ GenBank accession numbers are given in parentheses. 
RES3, and the NtPRp27-encoding gene (NTPRP27) in plants inoculated with the lps $\beta 2$ mutant were similar to those observed in plants inoculated with the $c g s$ mutant.

In general, results obtained with qRT-PCR confirmed those obtained with cDNA array analysis. Only a few divergences were found. For example, using cDNA arrays, DRRP was found to be twofold higher expressed in wild-type-inoculated roots than in roots infected with the cgs mutant (Table 1). However, no significant differences were found by qRT-PCR (Table 2). Some of the divergences might be explained by the sensitivity and the higher degree of specificity of qRT-PCR methodology. Thus, expression data for genes being members of large gene families with high degrees of sequence conservation have to be considered more cautiously. Therefore, discrimination between expression levels of highly similar genes might be difficult.

Accumulation of phenolic compounds in roots and nodules.

As reported above, a gene encoding a PAL was found to be strongly induced $21 \mathrm{dpi}$ with the cgs mutant. PAL is a key enzyme involved in the production of phenolic compounds (Baron and Zambryski 1995). To test whether such compounds were accumulated in nodule-like structures induced by the $c g s$ mutant, roots were treated with potassium permanganate and were examined using light microscopy at different postinoculation times (7, 15, and 28 days) (Fig. 1). At 7 and $15 \mathrm{dpi}$, roots inoculated with the $\operatorname{cgs}$ mutant showed strong stained regions, indicating the presence and accumulation of polyphenolic compounds (Fig. 1). In contrast, no phenolic compounds were observed in roots that were inoculated with the wild-type strain or in noninoculated control roots. Later during the course of nodulation ( $28 \mathrm{dpi}$ ), homogeneous brown staining was found in plants inoculated with the wild-type and cgs mutant; however, accumulation of phenolic compounds was significantly higher in roots inoculated with the $\operatorname{cgs}$ mutant strain than in roots inoculated with the wild-type strain (Fig. 1). Such enrichment also was observed in nodule-like structures induced by the $c g s$ mutant (Fig. 1).
Early nodule gene expression.

As reported above, expression of several early nodulins was altered in roots inoculated with the $\mathrm{cgs}$ mutant strain. Nodulelike structures that developed upon inoculation of roots with the cgs mutant did not harbor any bacteria. Because the mutant produces Nod factors normally (data not shown), we examined whether expression patterns of genes involved in early signaling events (NFR5, SYMRK, NIN, POLLUX, CASTOR, and ENOD2) were altered. For these experiments, RNA was extracted from roots 12,24 , and $48 \mathrm{~h}$ postinoculation (hpi) and 4, 7, 14, and 21 dpi.

No significant difference between strains was observed for the expression of NFR5, SYMRK, and CASTOR during nodule induction (Fig. 2), whereas POLLUX showed induced expression in roots inoculated with the $\operatorname{cgs}$ mutant 12 hpi. Similar transcript levels using wild-type rhizobia were observed only at $14 \mathrm{dpi}$ (Fig. 2).

The NIN gene encodes a putative transcription factor that is required for the formation of ITs and initiation of primordia (Schauser et al. 1999). According to previous reports (Radutoiu et al. 2003; Schauser et al. 1999), NIN shows an upregulation during the nodulation process induced by the wild-type strain. No transcriptional activation of NIN was observed in roots inoculated with the cgs mutant (Fig. 2).

$E N O D 2$ expression was described to be increased upon initiation of nodule cell differentiation and to require a functional NFR1 and NFR5 (Radutoiu et al. 2003). Analysis of ENOD2 gene expression revealed that the strong increment observed in roots inoculated with the wild-type strain between 7 and 21 dpi was not detected in roots inoculated with the cgs mutant strain (Fig. 2).

\section{DISCUSSION}

\section{cDNA array analysis.}

cDNA array analysis of plant genes was used to elucidate molecular differences between roots inoculated with wild-type and two rhizobial mutant strains (cgs and lps $\beta 2$ ).

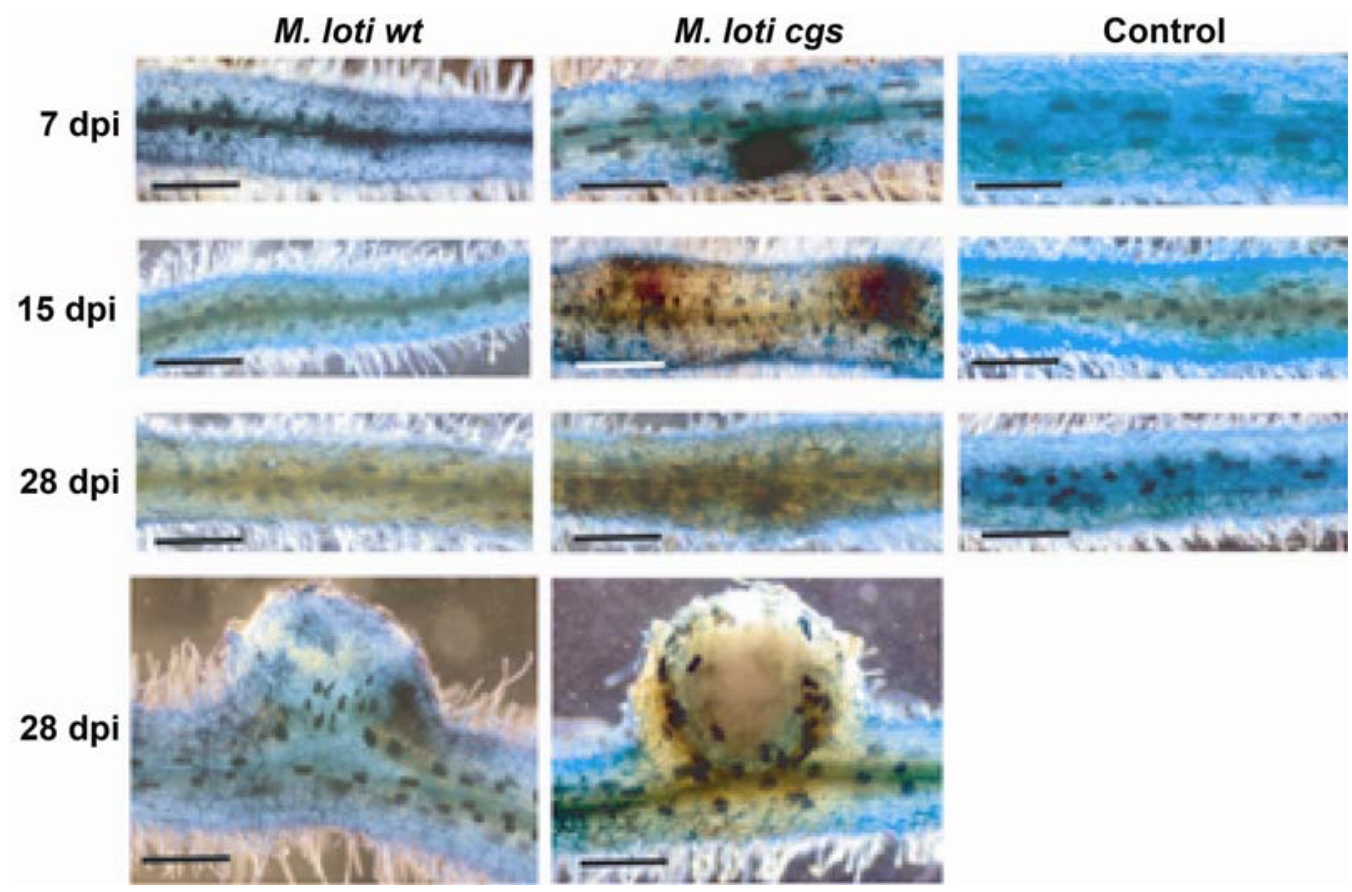

Fig. 1. Accumulation of phenolics compounds in roots and nodules of Lotus japonicus. Uninoculated and inoculated plants with the different strains of Mesorhizobium loti (wild-type [wt] or cyclic $\beta(1-2)$ glucan synthesis $[c g s]$ mutant) were harvested at several timepoints postinoculation (days postinoculation [dpi]), were treated with potassium permanganate, and were examined using light microscopy. Scale bar indicates $250 \mu \mathrm{m}$. 
Although induction of defense- and stress-responsive pathways during symbiotic interactions has been reported previously (Colebatch et al. 2004; El Yahyaoui et al. 2004; Kouchi et al. 2004; Liu et al. 2003; Manthey et al. 2004; Niehaus et al. 1993; Ramu et al. 2002; Santos et al. 2001; Vasse et al. 1993), the use of bacterial mutants enabled us to study expression of these systems in more detail.

Transcript profiles of roots 7 and 28 dpi revealed several genes to display increased expression levels in roots inoculated with the wild-type strain compared with those inoculated with the cgs mutant strain. Considering the defective nodule phenotype induced by the cgs mutant, we speculate that genes that lack induction by the mutant may be genes involved in nodule maturation. Consistent with this idea, most of these genes were found to be induced in roots with mature nodules containing wild-type rhizobia compared with uninoculated roots. Array results obtained at different time point postinoculation also suggest the existence of transient expression of some of the identified genes.

Fewer and generally less pronounced changes were observed in roots of plants inoculated with the lps $\beta 2$ mutant 28 dpi compared with the wild-type. These results are in agreement with the nodulation phenotype of this mutant that induces the formation of wild-type-like nodules. However, there is a delay of the expression of several genes at $7 \mathrm{dpi}$. Because lps $\beta 2$ displays no defect on the formation of ITs, it can be assumed that most of the genes differentially regulated might play roles in cell invasion or in the successive events of nodule development rather than in earlier steps of infection.

\section{Gene expression during the nodulation process analyzed by real-time RT-PCR.}

Nodulins, defense-, and redox-related genes. Genes with constantly increased expression during nodule development (ENOD40, GA-2 OXIDASE, F3H, SNAKIN-1, and NLJ21) were grouped. Expression of these genes seems to be related to the development of a fully active nodule because most of them were not expressed or displayed low expression in the inactive nodules formed by the cgs mutant.

GA-2 oxidase and F3H are involved in plant defense responses and were described previously as strongly induced in mature nodules (Kouchi et al. 2004). Nlj21, a glutamate-rich nodulin protein, also was associated with late nodule developmental events during nodule organogenesis in $L$. japonicus
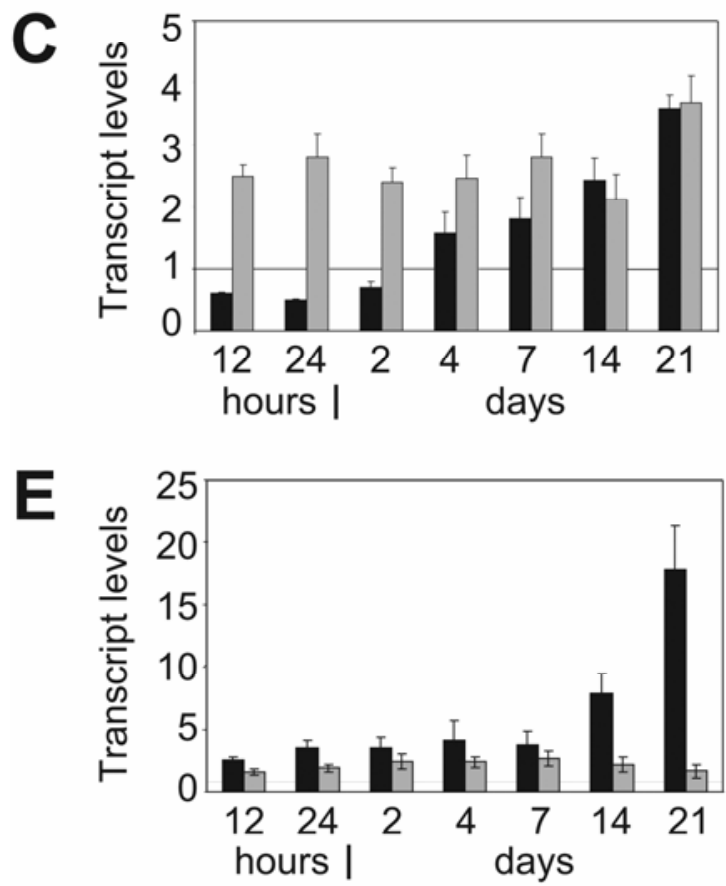
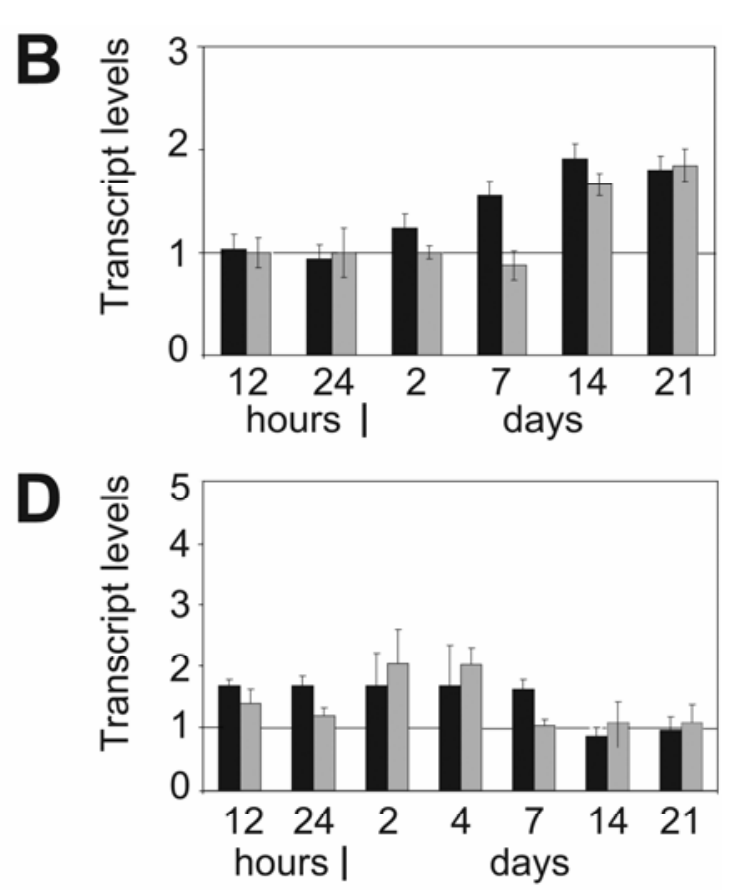

$\mathbf{F}$

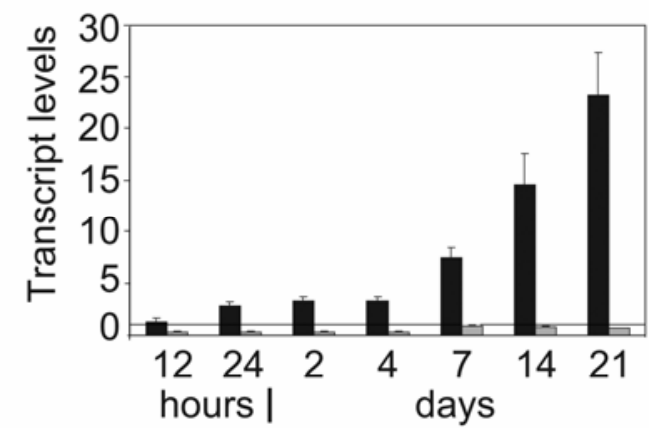

\section{M. loti wt \\ M. loti cgs}

Fig. 2. Real-time reverse-transcriptase polymerase chain reaction expression analysis of transcript levels of plant genes involved in Nod factor perception and early signaling. A, NFR5, B, SYMRK), C, POLLUX, D, CASTOR, E, ENOD2, and F, NIN expression was determined at different times postinoculation in roots of plants inoculated with Mesorhizobium loti wild-type (wt) strain (black bars) or with cyclic $\beta(1-2)$ glucan synthesis (cgs) mutant strain (gray bars). Expression levels are shown relative to un-infected roots at the same time point. The error bars indicate standard deviation. 
(Szczyglowski et al. 1998). Both GA-2 OXIDASE and NLJ21 expression were described to be repressed in ineffective sen 1 nodules (Suganuma et al. 2003).

Our results support the hypothesis that these two proteins are strictly associated with an active nodule because their expression was not induced in nonfunctional nodules formed by the cgs mutant.

Snakins form a large family of antimicrobial peptides in plants (Broekaert et al. 1995; Garcia-Olmedo et al. 1998, 2001). Among them, snakin-1 and -2 exhibited strong antimicrobial activity in potato plants (Berrocal-Lobo et al. 2002; Segura et al. 1999). Here, we report for the first time that snakin-1 also is induced during a symbiotic interaction. This gene was not found to be induced in roots that were inoculated with the cgs mutant; therefore, it can be suggested that such peptides might be involved in control of infection once plant cell invasion occurs.

A second group of genes exhibited a transient induction during intermediate stages of nodule development and a subsequent decrease. This group included several other defense (PR10-1, NLS-TIR-NBS, RES3, endo- $\beta$-1,4-glucanase-encoding gene, and NTPRP27) and redox (PX and SOD)-related genes. Increased expression of PR10-1 and NTPRP27 was reported previously during plant-pathogen interactions (Hadwiger et al. 1992; Liu et al. 2003; Okushima et al. 2000), and expression of a gene encoding for a putative endo- $\beta$-1,4-glucanase from $M$. truncatula was found to be induced in arbuscular mycorrhizal symbiosis (Liu et al. 2003). Also, an EST similar to endo- $\beta$-1,4-glucanase was found to accumulate in roots of M. truncatula during root symbiosis (Manthey et al. 2004).

A number of defense- and stress-related genes previously were reported to display transient expression during the $L$. japonicus-M. loti interaction (Kouchi et al. 2004) and during arbuscular mycorrhizal symbiosis in M. truncatula (Liu et al. 2003). Here, we found that, during the development of empty nodules induced by the cgs mutant strain, transient induction of the majority of the defense-related or stress-related genes did not occur.

In the inoculation with the $\operatorname{lps} \beta 2$ mutant, expression of $R E S 3$, NTPRP27, and $P X$ were reduced drastically when compared with wild-type inoculations. Although this suggests that regulation of these genes is linked to bacterial invasion, a direct role of LPS O-antigen on its induction cannot be ruled out.

Another enzyme frequently associated with plant host defense and plant stress is PAL (Pallas et al. 1996). PAL accumulation previously was correlated with the infection process in the Sinorhizobium meliloti-alfalfa interaction (Vasse et al. 1993). This enzyme is involved in the synthesis of phenolic compounds and an increased level of these molecules was observed in pseudonodules induced by $S$. meliloti EPSI $^{-}$mutants (Niehaus et al. 1993).

Some increment of $P A L$ expression was observed in roots inoculated with the wild-type strain; however, its expression was strongly induced in roots of plants inoculated with the $c g s$ mutant. Invading microorganisms have developed specialized mechanisms to modulate or avoid host defense responses (Chisholm et al. 2006). In rhizobia, bacterial polysaccharides, effectors proteins, and Nod factors were postulated to fulfill these functions (Bartsev et al. 2004; Bhagwat et al. 1999; Fraysee et al. 2003; Mitra and Long 2004; Perotto et al. 1994). Low levels of $P A L$ expression in roots inoculated with the wild-type strain compared with the $c g s$ mutant suggests that $P A L$ expression is controlled during wild-type interactions, a mechanism that is absent in the $\operatorname{cgs}$ mutant interaction. It was described that LPS from $S$. meliloti was able to suppress expression of several $M$. truncatula genes related to the plant response, including PAL (Tellstrom et al. 2007). Our experi- ments indicate that the presence of the bacterial components inside the ITs might be required for suppression of $P A L$ expression.

Genes involved in Nod factor perception and signal transduction. Several genes involved in Nod factor perception and early signal transduction that are essential for nodule organogenesis in L. japonicus have been cloned. Among them were the putative Nod factor receptor genes NFR1 and NFR5 (Madsen et al. 2003; Radutoiu et al. 2003); the symbiotic receptor-like kinase gene SYMRK (Stracke et al. 2002); NIN, a gene encoding a putative transcription factor required for IT formation and inception of the nodule primordia (Schauser et al. 1999); and genes such as POLLUX and CASTOR that were predicted to encode ion channels (Imaizumi-Anraku et al. 2005).

Although expression of NFR5, SYMRK, and CASTOR appeared not to be altered in roots inoculated with the $\operatorname{cgs}$ mutant, expression of POLLUX was significantly higher in roots inoculated with the cgs mutant than in roots inoculated with the wild-type strain. The results support earlier findings that expression of POLLUX is controlled by the bacteria (ImaizumiAnraku et al. 2005).

Another significant difference was found for the putative transcription factor $N I N$. In agreement with earlier results (Radutoiu et al. 2003), we observed NIN expression to be continuously increased during nodulation process. Such behavior was not observed in roots inoculated with the $\operatorname{cgs}$ mutant. Previous publications indicated that application of purified Nod factors on seedlings led to induction of NIN expression and negative regulation of POLLUX transcription (ImaizumiAnraku et al. 2005; Radutoiu et al. 2003). The cgs mutant normally secretes Nod factors and is effective in inducing root hair curling and nodule primordia. Thus, our results suggest that, to produce the differential expression of these genes, Nod factor perception also is required when wild-type bacteria are hosted inside ITs.

Apparently contradictory results were published for the expression of the ENOD2 gene during nodulation. Mitra and Long (2004) reported that bacterial mutants affected in their ability to invade the host root (exoA and $e x o H)$ did not induce expression of this nodulin in M. truncatula. On the other hand, expression of ENOD2 in empty nodules was induced by mutants affected in the cyclic glucan synthesis $(n d v B)$ but also by an exoA mutant in alfalfa (Dickstein et al. 1988). These conflicting findings were explained by the different developmental stages of nodule-like structures induced by these mutants and led to the suggestion that development of symbiosis is more tightly controlled in M. truncatula than in alfalfa (Mitra and Long 2004). Here, we described that, during the wild-type interaction with L. japonicus, ENOD2 expression was increased between 7 and $21 \mathrm{dpi}$, an effect that was not observed during interaction with the $c g s$ mutant. This could be an indication that the pseudonodules induced by $\operatorname{cgs}$ on L. japonicus were arrested in an early developmental stage.

\section{Concluding remarks.}

Analysis of the transcriptional profile of $L$. japonicus genes upon inoculation with $M$. loti wild-type and mutant strains affected in different steps of the symbiotic process led to the identification of several genes whose expression is related to the nodule bacterial invasion and nodule maturation. Several new genes that previously were associated with the plant-pathogen interactions were found to be differentially expressed, giving new insights into roles of plant defense systems during symbiotic interactions. Components of early recognition and signaling pathways also were found to be altered when using a bacterial mutant strain that is unable to invade the host root; 
therefore, these results support links between recognition of symbiotic bacteria and control of infection by classical plant defense systems.

\section{MATERIALS AND METHODS}

\section{Plant and rhizobial cultivation.}

M. loti strains were grown at $28^{\circ} \mathrm{C}$ in $\mathrm{AB}$ minimal medium (Douglas et al. 1985) supplemented with sucrose $(0.5 \%$ wt/vol). For growth of mutant bacteria, gentamicin was added to a final concentration of $30 \mu \mathrm{g} / \mathrm{ml}$.

L. japonicus GIFU B-129 seed were surface sterilized and pregerminated. Three-day-old seedlings were planted onto square petri dishes that contained quarter-strength B\&D medium (Broughton and Dilworth 1971) for sterile cultivation in a controlled environment. Plants were grown for 1 week before being inoculated with different $M$. loti strains at an optical density of 0.6 at $600 \mathrm{~nm}(10 \mu \mathrm{l} / \mathrm{plant})$. Plants were harvested directly into liquid nitrogen and stored at $-80^{\circ} \mathrm{C}$.

\section{cDNA array.}

Construction, design, and hybridization procedures of these arrays containing 9,600 redundant PCR-amplified EST clones from a nodule library was described previously (Colebatch et al. 2002a; Ott et al. 2005). In all, four replicates representing two independent experiments were performed for each condition analyzed.

\section{Quantitative real-time RT-PCR.}

Quantitative determination of relative transcript levels by Real Time RT-PCR was carried out according to Czechowski and associates (2004), except that total RNA was isolated from roots using the RNeasy plant mini kit (Qiagen, Hilden, Germany). Transcript levels were normalized to ubiquitin. Genespecific primers were designed using the Primer Express Software (Applied Biosystems, Foster City, CA, U.S.A.). Sequences of oligonucleotide primers used in RT-PCR experiments are shown in Supplementary Table C. In all, four replicates, representing two biological replicates, were performed for each condition analyzed. The tentative consensus (TC) repository can be found at the Gene Index Project website.

\section{Competition assay and \\ fluorescence microscopy experiments.}

Plasmids pDG71 (containing $g f p$ ) and pDG77 (containing DsRed) (Gage 2002) were transferred into M. loti lps $\beta 2$ and $M$. loti wild-type strain by triparental mating. For competition assay, $M$. loti lps $\beta 2 /$ pDG71 and wild-type strains/pDG77 were mixed together in 1:1 ratio and inoculated on $L$. japonicus plants as described previously (Gage 2002). At different times postinoculation, the occurrence of IT formation was evaluated by using fluorescence microscopy. Fluorescence microscopy experiments were made by using a Nikon ECLIPSE E600 EPIFL microscope. The filter set for fluorescence microscopy consisted of a 450- to 490-nm band-pass excitation filter and a 515-nm barrier filter for $g f p$-expressing $M$. loti lps $\beta 2$ and DsRed-expressing $M$. loti strain was imaged by using a 540- to 480-nm band-pass excitation filter and a 600- to 660-nm barrier filter. At 3 weeks postinoculation, five nodules were harvested, sterilized, and crushed in $\mathrm{AB}$ medium as described previously. To determine the relative proportions of the mutant strain with respect to the wild-type strain, serial dilutions were plated on $\mathrm{AB}$ sucrose $0.5 \%$ minimal medium with or without gentamicin. The experiment was performed in duplicates. The competitiveness index (CI) was calculated as the following ratio: $\mathrm{CFU}$ of mutant recovered from the nodule per $\mathrm{CFU}$ of total bacteria recovered from the nodule.
The cgs mutant strain harboring the pTB93F plasmid (Gage et al. 1996) was used to analyze the formation of ITs on $L$. japonicus as described previously (D'Antuono et al. 2005).

\section{Histochemical assay.}

For in situ localization of polyphenols accumulation, plants were inoculated with $M$. loti wild-type and $M$. loti $\operatorname{cgs}$ strains. Plants were harvested at different times postinoculation and stained as described previously (Vasse et al. 1993). Briefly, whole plants were fixed with a solution of $10 \%$ glutaraldehyde and then postfixed with a solution $0.04 \%$ potassium permanganate. After rising, plants were stained for 10 min with a $0.01 \%$ aqueous solution of methylene blue and finally cleared for 3 min with an aqueous solution of sodium hypochlorite. The plants were examined by bright-field or phase-contrast microscopy with a Nikon ECLIPSE E600 EPI-FL microscope.

\section{ACKNOWLEDGMENTS}

The project was supported by the grant from the Deutscher Akademischer Auslandienst Deutscher Akademischer Austauschdienst and from Fundación Antorchas (project number 14116-201) and by a grant from the Agencia Nacional de Promoción Científica y Tecnológica (PICT 2004 N0 20408).

\section{LITERATURE CITED}

Barnett, M. J., Toman, C. J., Fisher, R. F., and Long, S. R. 2004. A dualgenome symbiosis chip for coordinate study of signal exchange and development in a prokaryote-host interaction. Proc. Natl. Acad. Sci. U.S.A. 101:16636-16641.

Baron, C., and Zambrysky, P. C. 1995. The plant response pathogenesis, symbiosis, and wounding: Variations on a common theme? Annu. Rev. Genet. 29:107-129.

Bartsev, A. V., Deakin, W. J., Boukli, N. M., McAlvin, C. B., Stacey, G., Malnoe, P., Broughton, W. J., and Staehelin, C. 2004. NopL, an effector protein of Rhizobium sp. NGR234, thwarts activation of plant defense reactions. Plant Physiol. 134:871-879.

Berrocal-Lobo, M., Segura, A., Moreno, M., Lopez, G., García-Olmedo, F., and Molina, A. 2002. Snakin-2, an antimicrobial peptide from potato whose gene is locally induced by wounding and responds to pathogen infection. Plant Physiol. 128:951-961.

Bhagwat, A. A., Mithofer, A., Pfefer, P. E., Kraus, C., Spickers, N., Hotckiss, A., Ebel, J., and Keister, D. L. 1999. Further studies of the role of cyclic $\beta$-glucans in symbiosis. An $n d v C$ mutant of Bradyrhizobium japonicum synthesizes cyclodecakis-(1-3)- $\beta$-glucosyl. Plant Physiol. 119:1057-1064.

Brewin, N. J. 2004. Plant cell wall remodeling in the rhizobium-legume symbiosis. Crit. Rev. Plant Sci. 23:293-316.

Broekaert, W. F., Terras, F. R., Cammue, B. P., and Osborn, R. W. 1995. Plant defensins: Novel antimicrobial peptides as components of host defense system. Plant Physiol. 108:1353-1358.

Broughton, W. J., and Dilworth, M. J. 1971. Control of leghemoglobin synthesis in snake beans. Biochem. J. 125:1075-1080.

Caetano-Anolles, G., and Gresshoff, P. M. 1991. Plant genetic control of nodulation. Annu. Rev. Microbiol. 45:345-382.

Chisholm, S. T., Coaker, G., Day, B., and Staskawicz, B. J. 2006. Hostmicrobe interaction; shaping the evolution of the plant immune response. Cell 1224:803-814.

Colebatch, G., Kloska, S., Trevaskis, B., Freund, S., Altmann, T., and Udvardi, M. K. 2002a. Novel aspects of symbiotic nitrogen fixation uncovered by transcript profiling with cDNA arrays. Mol. Plant-Microbe Interact. 15:411-420

Colebatch, G., Trevaskis, B., and Udvardi, M. 2002b. Symbiotic nitrogen fixation research in the postgenomics era. New Phytol. 153:37-42.

Colebatch, G., Desbrosses, G., Ott, T., Krusell, L., Montanari, O., Kloska, S., Kopka, J., and Udvardi, M. K. 2004. Global changes in transcription orchestrate metabolic differentiation during symbiotic nitrogen fixation in Lotus japonicus. Plant J. 39:487-512.

Cook, D., Dreyer, D., Bonnet, D., Howell, M., Nony, E., and Vandenbosch, K. 1995. Transient induction of a peroxidase gene in Medicago truncatula precedes infection by Rhizobium meliloti. Plant Cell 7:43-55.

Czechowski, T., Bari, R. P., Stitt, M., Scheible, W. R., and Udvardi M, K, 2004. Real-time RT-PCR profiling of over 1,400 Arabidopsis transcription factors: Unprecedented sensitivity reveals novel root- and shootspecific genes. Plant J. 38:366-379. 
D'Antuono, A. L., Casabuono, A., Couto, A., Ugalde, R. A., and Lepek, V. C. 2005. Nodule development induced by Mesorhizobium loti mutant strains affected in polysaccharide synthesis. Mol. Plant-Microbe Interact. 18:446-457.

Dickstein, R., Bisseling, T., Reinhold, V. N., and Ausubel, F. M. 1988. Expression of nodule-specific genes in alfalfa root nodules blocked at an early stage of development. Genes Dev. 2:677-687.

Douglas, C. J., Staneloni, R. J., Rubin, R. A,, and Nester, E. W. 1985. Identification and genetic analysis of an Agrobacterium tumefaciens chromosomal virulence region. J. Bacteriol. 161:850-860.

El Yahyaoui, F., Kuste, H., Ben Amor, B., Hohnjec, N., Puhler, A., Becker, A., Gouzy, J., Vernie, T,, Gough, C., Niebel, A., Godiard, L., and Gamas, P. 2004. Expression profiling in Medicago truncatula identifies more than 750 genes differentially expressed during nodulation, including many potential regulators of the symbiotic program. Plant Physiol. 136:3159-3176.

Endre, G., Keresz, A., Kevei, Z., Mihacea, S., Kalo, P., and Kiss, G. B 2002. A receptor kinase gene regulating symbiotic nodule development. Nature 417:962-966.

Fedorova, M., van de Mortel, J., Matsumoto, P. A., Cho, J., Town, C. D., VandenBosch, K. A., Gantt, J. S., and Vance, C. P. 2002. Genome-wide identification of nodule-specific transcripts in the model legume Medicago truncatula. Plant Physiol. 130:519-537.

Fraysse, N., Couderc, F., and Poinsot, V. 2003. Surface polysaccharide involvement in establishing the rhizobium-legume symbiosis. Eur. J. Biochem. 270:1365-1380.

Gage, D. J. 2002. Analysis of infection thread development using Gfp- and DsRed-expressing Sinorhizobium meliloti. J. Bacteriol. 184:7042-7046.

Gage, D. J. 2004. Infection and invasion of roots by symbiotic, nitrogenfixing rhizobia during nodulation of temperate legumes. Microbiol. Mol. Biol. Rev. 68:280-300.

Gage, D. J., Bobo, T., and Long, S. R. 1996. Use of green fluorescent protein to visualize the early events of symbiosis between Rhizobium meliloti and alfalfa (Medicago sativa). J. Bacteriol. 178:7159-7166.

Gamas, P., Niebel, F. de C., Lescure, N., and Cullimore, J. 1996. Use of a subtractive hybridization approach to identify new Medicago truncatula genes induced during root nodule development. Mol. Plant-Microbe Interact. 9:233-242.

García-Olmedo, F., Molina, A., Alamillo, J. M., Rodriguez-Palenzuela, P. 1998. Plant defense peptides. Biopolymers 47:479-491.

García-Olmedo, F., Rodríguez-Palenzuela, P., Molina, A., Alamillo, J. M., Lopez-Solanilla, E., Berrocal-Lobo, M., and Poza-Carrión, C. 2001. Antibiotic activities of peptides, hydrogen peroxide and peroxynitrite in plant defence. FEBS (Fed. Eur. Biochem. Soc.) Lett. 498:219-222.

Godiard, L., Niebel, A., Micheli, F., Gouzy, J., Ott, T., and Gamas, P. 2007. Identification of potential regulators of the Medicago truncatulaSinorhizobium meliloti symbiosis using a large-scale suppression subtractive hybridization approach. Mol. Plant-Microbe Interact. 20:321332

Günther, C., Schlereth, A., Udvardi, M., and Ott, T. Metabolism of reactive oxygen species is attenuated in leghemoglobin-deficient nodules of Lotus japonicus, Mol. Plant-Microbe Interact. 20:1596-1603.

Hadwiger, L. A., Chiang, C. C., and Horovitz, D. 1992. Expression of disease resistance response genes in near-isogenic pea cultivars following challenge by Fusarium oxysporum/ race 1. Physiol. Mol. Plant Pathol. 40:259-270.

Imaizumi-Anraku, H., Takeda, N., Charpentier, M., Perry, J., Miwa, H., Umehara, Y., Kouchi, H., Murakami, Y., Mulder, L., Vickers, K., Pike, J., Downie, J. A., Wang, T., Sato, S., Asamizu, E., Tabata, S., Yoshikawa, M., Murooka, Y., Wu, G.-J., Kawaguchi, M., Kawasaki, S., Parniske, M., and Hayashi, M. 2005. Plastid proteins crucial for symbiotic fungal and bacterial entry into plant roots. Nature 433:527-531.

Jimenez-Zurdo, J. I., Frugier, F., Crespi, M. D., and Kondorosi, A. 2000. Expression profiles of 22 novel molecular markers for organogenetic pathways acting in alfalfa nodule development. Mol. Plant-Microbe Interact. 13:96-106.

Journet, E. P., van Tuninen, D., Gouzy, J., Crespeau, H., Carreau, V., Farmer, M. J., Niebel, A., Schiex, T., Jaillon, O., Chatagnier, O., Godiard, L., Micheli, F., Kahn, D., Gianinazzi-Pearson, V., and Gamas, P. 2002. Exploring root symbiotic programs in the model legume Medicago truncatula using EST analysis. Nuclei Acids Res. 30:5579-5592.

Kouchi, H., Shimomura, K., Hata, S., Hirota, A., Wu, G., Kumagai, H., Tajima, S., Suganuma, N., Suzuki, A., Aoki, T., Hayashi, Yakoyama, T., Ohyama, T., Asamizu, E., Duwata, C., Shibata, D., and Tabata, S. 2004. Large-scale analysis of gene expression profiles during early stages of root nodule formation in a model legume, Lotus japonicus. DNA Res. 11:263-274

Lamblin, A. F. J., Crow, J. A., Johnson, J. E., Silverstein, K. A. T., Kunau, T. M., Kilian, A., Benz, D., Stromvik, M., Endre, G., VandenBosch, K. A., Cook, D. R., Young, N. D., and Retzel, E. F. 2003. MtDB: A data- base for personalized data mining of the model legume Medicago truncatula transcriptome. Nucleic Acids Res. 31:196-201.

Lepek, V. C., and D'Antuono, A. L. 2005. Bacterial surface polysaccharides and their role in the rhizobia-legume association. Lotus Newsl. 35:93-105.

Limpens, E., Franken, C., Smit, P., Willemse, J., Bisseling, T., and Geurts, R. 2003. LysM domain receptor kinases regulating rhizobial Nod factor-induced infection. Science 302:630-633.

Liu, J., Blaylock, L. A., and Endre, G. 2003. Transcript profiling coupled with spatial expression analyses reveals genes involved in distinct developmental stages of an arbuscular mycorrhizal symbiosis. Plant Cell 15:2106-2123.

Lohar, D. P., Sharapova, N., Endre, G., Peñuela, S., Samac, D., Town, C., Silverstein, K. A. T., and VandenBosch, K. A. 2006. Transcript analysis of early nodulation events in Medicago truncatula. Plant Physiol. 140:221-234.

Madsen, E. B., Madsen, L. H., Radutoiu, S., Olbryt, M., Rakwalska, M., Szczyglowski, K., Sato, S., Kaneko, T., Tabata, S., Sandal, N., and Stougaard, J. 2003. A receptor kinase gene of the LysM type is involved in legume perception of rhizobial signals. Nature 425:637-640.

Manthey, K., Krajinski, F., Hohnjec, N., Firnhaber, C., Puhler, A., Perlick, A. M., and Kuster, H. 2004. Transcriptome profiling in root nodules and arbuscular mycorrhiza identifies a collection of novel genes induced during Medicago truncatula root endosymbioses. Mol. Plant-Microbe Interact. 17:1063-1077.

Matamoros, M. A., Dalaton, D. A., Ramos, J., Clemente, M. R., Rubio, M. C., and Becana, M. 2003. Biochemistry and molecular biology of antioxidants in the rhizobia-legume symbiosis. Plant Physiol. 133:499509.

Mitra, R. M., and Long, S. R. 2004. Plant and bacterial symbiotic mutants define three transcriptionally distinct stages in the development of the Medicago truncatula/Sinorhizobium meliloti symbiosis. Plant Physiol. 134:595-604

Niehaus, K., Kapp, D., and Puhler, A. 1993. Plant defence and delayed infection in alfalfa pseudonodules induced by an exopolysaccharide (EPS I)-deficient Rhizobium meliloti mutant. Planta 190:415-425.

Okushima, Y., Koizumi, N., Kusano, T., and Sano, H. 2000. Secreted proteins of tobacco cultured BY2 cells: Identification of a new member of pathogenesis- related proteins. Plant Mol. Biol. 42:479-488.

Ott, T., Krusell, L., Freund, S., and Udvardi, M. 2005. Lotus transcriptome analysis using cDNA arrays. Pages 149-155 in: The Lotus japonicus Handbook. A. J. Márquez, ed. Kluwer, Dordrecht, The Netherlands.

Pallas, J., Paiva, N. L., Lamb, C. J., and Dixon, R. A. 1996. Tobacco plants epigenetically suppressed in phenylalanine ammonia-lyase expression do not develop systemic acquired resistance in response to infection to tobacco mosaic virus. Plant J. 10:281-293.

Peiter, E., Sun, J., Heckmann, A. B., Venkateshwaran, M., Riley, B. K., Otegui, M. S., Edwards, A, Freshour, G., Hahan, M. G., Cook, D. R., Sanders, D., Oldroyd, G. D., Downie, J. A., and Ané, J.-M. 2007. The Medicago truncatula DMI1 protein modulates cytosolic calcium signaling. Plant Physiol. 145:192-203.

Perotto, S., and Brewin, N. J. 1994. Cytological evidence for a host defense response that reduces cell and tissue invasion in pea nodules by lipopolysaccharide-defective mutants of Rhizobium leguminosarum strain 3841. Mol. Plant-Microbe Interact. 7:99-112.

Radutoiu, S., Madsen, L. H., Madsen, E. B., Felle, H. H., Umehara, Y., Gronlund, M., Sato, S., Nakamura, Y., Tabata, S., Sandal, N., and Stougaard, J. 2003. Plant recognition of symbiotic bacteria requires two LysM receptor-like kinases. Nature 425:585-592.

Ramu, S. K., Peng, H., and Cook, D. R. 2002. Nod factor induction of reactive oxygen species production is correlated with expression of the early nodulin gene ripl in Medicago truncatula. Mol. Plant-Microbe Interact. 15:522-528.

Santos, R., Herouart, D., Sigaud, S., Touati, D., and Puppo, A. 2001. Oxidative burst in alfalfa-Sinorhizobium meliloti symbiotic interaction. Mol. Plant-Microbe Interact. 14:86-89.

Schauser, L., Roussis, A., Stiller, J., and Stougaard, J. 1999. A plant regulator controlling development of symbiotic root nodules. Nature 402:191-195.

Segura, A., Moreno, M., Madueño, F., Molina, A., and García-Olmedo, F. 1999. Snakin-1, a peptide from potato that is active against plant pathogens. Mol. Plant-Microbe Interact. 12:16-23.

Spaink, H. P. 2000. Root nodulation and infection factors produced by rhizobial bacteria. Annu. Rev. Microbiol. 54:257-288.

Starker, C. G., Parra-Colmenares, A. L., Smith, L., Mitra, R. M., and Long, S. R. 2006. Nitrogen fixation mutants of Medicago truncatula fail to support plant and bacterial symbiotic gene expression. Plant Physiol. 140:671-680.

Stougaard, J. 2000. Regulators and regulation of legume root nodule development. Plant Physiol. 124:531-540. 
Stracke, S., Kistner, C., Yoshida, S., Mulder, L., Sato, S., Kaneko, T. Tabata, S., Sandal, N., Stougaard, J., Szczyglowski, K., and Parniske, M. 2002. A plant receptor-like kinase required for both bacterial and fungal symbiosis. Nature 417:959-962.

Suganuma, N., Nakamura, Y., Yamamoto, M., Ohta, T., Koiwa, H., Akao, S., and Kawaguchi, M. 2003. The Lotus japonicus Sen1 gene controls rhizobial differentiation into nitrogen-fixing bacteroids in nodules. Mol. Genet. Genomics 269:312-320.

Szczyglowski, K., Hamburger, D., Kapranov, P., and de Bruijn, F. J. 1997. Construction of a Lotus japonicus late nodulin expressed sequence tag library and identification of novel nodule-specific genes. Plant Physiol. 114:1335-1346.

Szczyglowski, K., Shaw, R. S., Wopereis, J., Copeland, S., Hamburger, D., Kasiborski, B., Dazzo, F. B., and De Bruijn, F. J. 1998. Nodule organogenesis and symbiotic mutants of the model legume Lotus japonicus. Mol. Plant-Microbe Interact. 11:684-697.

Tellstrom, V., Usadel, B., Thimm, O., Stitt, M., Kuster, H., and Niehaus, K. 2007. The lipopolysaccharide of Sinorhizobium meliloti suppresses defense-associated gene expression in cell cultures of the host plant Medicago truncatula. Plant Physiol. 143:825-837.
Tesfaye, M., Samac, D. A., and Vance, C. P. 2006. Insights into symbiotic nitrogen fixation in Medicago truncatula. Mol. Plant-Microbe Interact. 19:330-341.

Udvardi, M. K., and Day, D. A., 1997. Metabolite transport across symbiotic membranes of legume nodules. Annu. Rev. Plant Physiol. Plant Mol. Biol. 48:493-523.

Vasse, J., de Billy, F., and Truchet, G. 1993. Abortion of infection during the Rhizobium meliloti-alfalfa symbiotic interaction is accompanied by a hypersensitive reaction. Plant J. 4:555-566.

Zuanazzi, J. A. S., Clergeot, P. H., Quirion, J.-C., Husson, H. P., Kondorosi, A., and Ratet, P. 1998. Production of Sinorhizobium meliloti nod gene activator and repressor flavonoids from Medicago sativa roots. Mol. Plant-Microbe Interact. 11:784-794.

\section{AUTHOR-RECOMMENDED INTERNET RESOURCE}

The Dana Farber Cancer Institute and Harvard School of Public Health Gene Index Project website:

compbio.dfci.harvard.edu/tgi/cgi-bin/tgi/gimain.pl?gudb=1_japonicus 